\title{
O DISCURSO POLITICO DO AUTORRETRATO EM ORIANA DUARTE
}

\author{
ANA CAROLINA MAGALHÃES SALVI \\ https://orcid.org/0000-0002-5722-2216 \\ Universidade Federal de Pernambuco
}

RESUMO Este texto propõe analisar um discurso político presente no trabalho de Oriana Duarte partindo da compreensão de seu corpo como híbrido ao transmutar-se constantemente em identidades instáveis e desterritorializadas, configurando uma identidade ciborgue que contraria as elaborações tradicionais e normativas do que é um corpo feminino na arte e na sociedade. Para tanto, toma-se como referência Butler (2000; 2003) e a ideia de gênero como categoria socialmente construída e, portanto, portadora de certas expectativas de performatividade em sociedade. Destarte, constrói-se uma diretriz que promove diálogo entre escrita de si como prática de liberdade diante das estruturas de poder e o autorretrato. A partir de entrevista com a artista e mergulho em sua poética, adotando como eixo de análise o autorretrato fotográfico $A$ Selvagem Sabedoria, foi desenhada uma cartografia que identifica os contornos das estruturas sociais envolvidas na problemática da pesquisa e que percorre a subjetividade e corpo desejante da artista. Assim, esse corpo desobediente a regras expressa um fazer político na prática de artistas mulheres, que ocuparam tradicionalmente na História da Arte eurocêntrica hegemônica uma posição de objeto de desejo atrelado ao olhar masculino.

Palavras-chave: Gênero. Arte contemporânea. Corpo. Autorretrato. Oriana Duarte.

\section{ABSTRACT THE POLITICAL DISCOURSE OF THE SELF-PORTRAIT IN ORIANA DUARTE}

This paper aims to analyse a political discourse in the production of Oriana Duarte, engendering from the understanding of her body as hybrid as it transmutes itself constantly into unstable and unterritorialized identities, constituting a cyborg identity that trespasses the traditional normative fabrications of what a female body should be in art and society. Therefore, Butler $(2000 ; 2003)$ is taken 
as a reference based on the notion of gender as a category socially manufactured and, thus, bearer of certain expectations of social performativity. From this standpoint, a guideline that furthers dialogue between the self writing and practice of freedom before power structures and the making of self-portrait. Having interview as main source, and adopting as analytical axis the photographic self-portrait A Selvagem Sabedoria, a cartography that identifies the contours of the social structures involved in the problematics of this paper was drawn, traveling through the subjectivity of the artist's yearning body. Thus, this body defiant of rules expresses a political doing in the practice of female artists, who have traditionally occupied a position of object of desire attached to a male gaze in the Eurocentric and hegemonic Art History.

Keywords: Gender. Contemporary art. Body. Self-Portrait. Oriana Duarte.

\section{RESUMEN EL DISCURSO POLÍTICO DEL AUTORRETRATO EN}

\section{ORIANA DUARTE}

Lo texto propone analizar un discurso político presente en el trabajo de Oriana Duarte a partir de la comprensión de su cuerpo como un híbrido al transmutarse constantemente en identidades inestables y desterritorializadas, configurando una identidad cyborg que contradice las elaboraciones tradicionales y normativas de lo que es un cuerpo femenino en arte y sociedad. Para eso, Butler (2000; 2003) se toma como referencia y la idea del género como una categoría socialmente construida y, por lo tanto, portadora de ciertas expectativas de performatividad en la sociedad. Por lo tanto, se construye una directriz que promueve el diálogo entre escribir uno mismo como una práctica de libertad frente a las estructuras de poder y el autorretrato. A partir de una entrevista con la artista y de sumergirse en su poética, adoptando el autorretrato fotográfico A Selvagem Sabedoria como eje de análisis, se dibujó una cartografía que identifica los contornos de las estructuras sociales involucradas en el problema de investigación y que atraviesa la subjetividad y el cuerpo deseoso de artista Por lo tanto, este cuerpo desobediente a las reglas expresa una práctica política en la práctica de las artistas femeninas, que tradicionalmente ocuparon en la hegemónica Historia del Arte Eurocéntrico una posición de objeto de deseo vinculada a la mirada masculina.

Palabras clave: Género. Arte Contemporaneo. Cuerpo. Autorretrato Oriana Duarte. 


\section{Introdução}

A narrativa da História da Arte carrega consigo uma tradição eurocêntrica e portadora de olhar verticalizado naquilo que concerne os papéis a serem desempenhados pela/os sujeita/os. Enquanto ao feminino era perpetuado o posto de objeto de contemplação, a figura masculina fruía do posto de sujeito artista, fomentando uma forte tradição do corpo nu feminino como comodidade cultural na arte, na qualidade de objeto de desejo masculino e negadas a possibilidade criativa. Assim, perpetuou-se a crença desse corpo passivo e limitado ao papel de musa-objeto, restrito a essa condição de subjugação fortalecida no sistema patriarcal. Essa lógica perdurou por séculos de forma institucionalizada, sendo as mulheres inclusive impedidas de acessarem o ensino formal e as academias de belas artes até o fim do século XIX, onde a vida artística acontecia e era legitimada, ostentando a segregação e polaridade dos gêneros tão presente nesse esquema de sociedade patriarcal (ZACCARA, 2017).

Operante numa orientação da divisão social dos espaços, a figura feminina foi designada ao lar, distante da vida pública, o que acabava por também limitar as experiências, contrastando com a amplitude de experiências disponiveis aos sujeitos em livre circulação nos espaços públicos. Essa situação limitou também os motivos artísticos a serem explorados por essas sujeitas, cujos temas recaíam na vida cotidiana do lar e, em muitos casos, a si mesmas, tornando o autorretrato um motivo bastante comum entre artistas mulheres. No entanto, seja ironicamente ou poeticamente, o autorretrato passou a ser utilizado também como forma de fazer-se visivel, de tornar pública e existente suas erudições, e com isso diversas artistas incorporaram o ofício da pintura, e outras atividades intelectuais, nas obras (BOTTI, 2005).
Convém destacar que essa lógica de arte fez parte de uma tradição que entrou em conflito em meados do século $X X$, em que a crise econômica europeia do pós-guerra ocasionou o transporte do centro cultural para os Estados Unidos, na época em plena ascensão econômica e expansão do sistema capitalista, o que trouxe consigo a reprodutibilidade em massa, consumo sem reflexão, exploração do trabatho em larga escala e expansão da arte como mercadoria. Como resposta a essa condição mercadológica, artistas movimentaram-se numa busca por dispositivos não comercializáveis, causando ruptura nas plataformas de expressão artística e quebrando o duopólio da pintura e escultura (ARCHER, 2001). A partir de então, a lógica da história da arte, enquanto movimento sucessivo, perdeu o sentido, e os campos expressivos tornaram-se diversificados e simultâneos.

Consequentemente, este se apresenta o momento em que o corpo transmuta de objeto de narrativa externa para suporte expressivo, dando espaço ao crescimento da performance que tanto explorou e aprofundou esta temática. As possibilidades narrativas emergentes junto a esse giro expressivo aproximaram política e arte, e grupos antes marginalizados nessa organização puderam fazer ecoar vozes. As mulheres que tradicionalmente haviam sido negadas a possibilidade criativa e permitidas quase unicamente como objeto de desejo masculino, com corpos narrados por um olhar externo, transformaram o pessoal em político, buscaram a emancipação e levantaram denúncia das opressões, trazendo a luta por igualdade para o campo da arte.

Neste período destacaram-se as inquietações de teóricas feministas como Linda Nochlin acerca do silêncio referente à participação de artistas mulheres no destaque dos acontecimentos históricos, promovendo a escavação arqueológica pela história à procu- 
ra delas. Foi a partir dos estudos inaugurais desse período que a desigualdade de oportunidades das sujeitas femininas na produção artística foi levantada como justificativa desse silêncio, abrindo discussão para várias outras problematizações concernindo as identidades e grupos marginalizados nessa esfera. Houve, então, uma reformulação geral do papel que as mulheres haviam ocupado e poderiam ocupar na arte.

Esse momento revela artistas como Cindy Sherman ${ }^{1}$ e provocação diante dos estereótipos de feminilidade no cinema, Judy Chicago e a obra Dinner Party² (1975-1979) em que dispõe um banquete repleto de personagens históricas femininas, ou mesmo Nan Goldin e a denúncia da violência doméstica sofrida em um autorretrato fotográfico em $1984^{3}$, e Ana Mendieta e as ações performáticas de denúncia de violências de gênero em Rape Scene (1973).4. Arte se expande enquanto campo de contestação e insubordinação ao sistema, ela torna visivel as lutas que antes haviam sido silenciadas nos lares, nos espaços invisiveis da sociedade.

Esse breve panorama introdutório pretende situar o plano no qual o artigo se encontra. Assim, é justo dentro desse contexto pós-moderno de multiplicidade e simultaneidade que Oriana Duarte inicia sua jornada artística. Nascida na Paraíba em 1966, Oriana traçou um percurso acadêmico e artístico centrado no corpo e suas possibilidades transgressoras, híbridas, e definidas por si mesma como pertencente a uma "zona de fronteiras", a fronteira aqui podendo ser encarada como um não-lugar, uma

1 Fonte: https://www.moma.org/learn/moma_learning/cindy-sherman-untitled-film-stills-1977-80/

2 Fonte: https://www.brooklynmuseum.org/exhibitions/dinner_party

3 Fonte: https://www.tate.org.uk/art/artworks/goldinnan-one-month-after-being-battered-p78045

4 Para maiores informações ver: GARCIA, C. SCHUCK, E. O feminismo de Ana Mendieta no campo das artes visuais. Seminário internacional Fazendo Gênero 11 \& 13th Women's Worlds Congress (Anais eletrônicos). Florianópolis, 2017. zona de possibilidades onde não há fixidez em espaços pré-estabelecidos. Esse não-lugar se apresenta como atitude constante em seu trabalho, que repetidamente busca experiências espaciais híbridas e extracorpóreas através de performances em que transforma seu corpo, seja em corpo-cidade, como em Playground (1995), onde instalações refletiam a forma com a qual se relacionava com a cidade do Recife, seja na experiência de tornar-se edificio em Dos Heteróclitos (2000-2002) ou tornar-se barco em Plus Ultra (2006-2011). Inaugurando a série de trabalhos com o corpo surge A Selvagem Sabedoria (2004), autorretrato com cobracipó que faz alusão direta à Le violon d'Ingres (1924) de Man Ray. Através de um palimpsesto, um hábito antigo que consistia em raspar as escrituras anteriores do pergaminho para dar espaço a novas, a artista raspa as significações anteriores de um corpo feminino passivo e objetificado colocando-se como sujeita (cri)ativa.

À vista disto, busco desenhar uma narrativa que discuta formas subjetivadoras, e, portanto, insurgentes de um fazer artístico feminino, entendendo A Selvagem Sabedoria como parte dos desmanchamentos de mundo propostos por uma cartografia traçada junto à ação micropolítica de uma subjetividade desterritorializada. Para tanto, trago como suporte o corpo híbrido e a identidade ciborgue de Donna Haraway (2009), somada à perspectiva de Michel Foucault (1979) sobre a importância da emancipação da subjetividade e da transformação do cotidiano como insurgência diante dos sistemas de poder, associadas a uma prática de liberdade contida na escrita de si - neste trabalho tratada pelo autorretrato - especialmente quando associada à narrativa de identidades políticas tradicionalmente silenciadas, como defendido por Margareth Rago (2013).

Em concordância com Donna Haraway em seu artigo Saberes localizados (1995), penso que a produção de conhecimento sobre mulhe- 
res por mulheres, ou qualquer outra forma de conhecimento horizontal e não hegemônico, é uma forma de resistência diante da herança de silenciamento que rodeia nossa história, uma possibilidade de desconstrução dessa lógica e transformação na construção de saberes. A cartografia, como proposta de metodologia de pesquisa, planeia a construção da subjetividade, e o acompanhar de processos que posicionam a/o sujeita/o narrada/o ativamente na composição. Tecem-se os cruzamentos entre a pesquisa (auto)biográfica e cartografia na subjetivação e proposição de um fazer político, em trazer à tona a experiência de sujeito que compõe e reflete os processos sócio históricos, estabelecendo um "diálogo entre o individual e o sociocultural" (ABRAHÃO, 2003, p. 81), entre as micropolíticas e macropolíticas.

É importante situar também que apesar de ser um campo em expansão, há escassez na produção de conhecimento que discuta o autorretrato como prática potencialmente transformadora através da análise de uma obra central, principalmente na língua portuguesa, visto que as principais leituras do tema que trago dizem respeito ou à prática do autorretrato sem relação direta a questões de gênero (GATTI, 2009) ou toma como foco uma análise amplificada acerca da frequência deste motivo entre artistas mulheres na contemporaneidade (BOTTI, 2005). Trago, então, o encontro de diversos campos do saber na intenção de construir uma pesquisa que discuta criticamente o fazer arte.

Para tal, foi escolhida a cartografia (BARROS e PASSOS, 2014) como metodologia de construção da pesquisa devido ao caráter não-descritivo e móvel no desenvolvimento dos procedimentos e suportes teóricos. Há também o aspecto sentimental dessa cartografia, que se faz no destaque dos processos de desejo e subjetivação da artista, nosso foco de investigação, investindo no destaque do corpo vibrá- til muito além dos planos estritamente visíveis (ROLNIK, 2016). Em uma pesquisa cartográfica não há resultados a serem apresentados, mas realidades a serem construídas, devires possiveis.

A pesquisa mostra a potência que carregam corpos instáveis e híbridos, que se desfazem das máscaras obsoletas de um formato de identidade, e que por sua instabilidade desestruturam as regras anteriores de obediência e controle dos corpos baseada na binaridade. Também destacamos a importância que um fazer artístico autobiográfico pode ter nesse contexto, e que é possível com uma imagem raspar significações anteriores ultrapassadas e emancipar-se nesse processo auto-narrativo, em produção de verdade autogovernada.

\section{Metodologia}

A pesquisa desenhou-se como uma cartografia, que segundo Suely Rolnik (2016) "acompanha e se faz ao mesmo tempo que o desmanchamento de certos mundos - sua perda de sentido - e a formação de outros: mundos que se criam para expressar afetos contemporâneos, em relação aos quais os universos vigentes tornam-se obsoletos", ou seja, trata-se de acompanhar subjetividades que oferecem possibilidades de novas verdades de sujeita/o, e consequentemente de mundo. Esse plano de análise e metodologia de construção de narrativa provoca os atritos entre o olho visivel - os marcadores sociais fixos - e o corpo vibrátil as transformações do desejo e subjetividade. Construir uma cartografia significa não apenas descrever uma situação, mas produzir significados outros, como descrito no trecho: "não há neutralidade do conhecimento, pois toda pesquisa intervém sobre a realidade mais do que apenas a representa ou constata um discurso cioso das evidências" (BARROS e PASSOS, 2015, p.20). 
O percurso metodológico contou com dois momentos principais: a revisão bibliográfica pertinente à problemática da pesquisa - a mulher artista e os dispositivos de poder que the atravessam - e o desenho da cartografia a partir de entrevista com a artista. Primeiramente foram identificadas as estruturas do olho visível que aprisionam as possibilidades de ser-no -mundo das mulheres, percorrendo a categoria mulher como construção histórica e social, como parte de uma rede de ações de poder atreladas à noção binária e normativa de gênero e sexualidades, acompanhando as formas de atuação das estruturas de poder na disciplinação dessas sujeitas. Esse momento é caracterizado como o desenho do mapa das estruturas visiveis, compreendido por Suely Rolnik (2016) como o movimento do olho visivel, daquilo que é aparente e pretende ser estático, é também o campo da macropolítica, em que as intensidades da subjetividade dos indivíduos pouco são levadas em consideração.

O segundo movimento da cartografia tratou de apresentar Oriana, compreendendo que na arte a relação artista-objeto-espectador contém e reflete as relações sociais que cada um desempenha, ação que por si só já desloca os significados e lugares que ocupam. Apresentar o desejo como força-motriz no trabalho de Oriana Duarte significa acompanhar as linhas que percorrem o seu processo criativo, significa colocar em primeiro plano os desejos que fervem e transmutam-se em performance, texto ou matéria. Esse momento mergulha em escritos da própria artista sobre seu trabalho, em escritos de terceiros sobre o mesmo e investiga, através de entrevistas diretas entre pesquisadora e artista, tudo que rodeia seu fazer.

A entrevista numa cartografia incorpora sua máxima, pois configura espaço aberto para que os efeitos de interação entre pesquisadora, sujeita narrada e suporte teórico escapem às variáveis, em justaposições ativadas a partir do lugar de cada uma. Os percursos teóricometodológicos foram fruto dos encontros afetivos na conversa direta com Oriana, e foi através das inquietações da minha caminhada que pude captar o corpo vibrátil para além da obra.

Após o levantamento bibliográfico, foram realizadas duas entrevistas com Oriana Duarte. A primeira delas buscou entender seu processo criativo, trabalho artístico e experiência de vida. A segunda entrevista visou aprofundar as questões do corpo como forma de arte e em específico abordar a obra central $A$ Selvagem Sabedoria e investigar se, para a artista, há um discurso político nela e qual, de forma a responder os objetivos da pesquisa.

A partir de então, surgiu a identidade híbrida e vivência ciborgue, conceitos próprios da pós-modernidade, segundo Donna Haraway (2009), e a potência que carrega consigo essa identidade fluida e desterritorializada no desmanchamento de estruturas obsoletas. A análise se debruçou então, em discutir um fazer artístico fluido e cujo dispositivo principal é o corpo, para pensar a escrita de si e a emancipação desse criar-se ao narrar-se, especialmente se pensado na narrativa autobiográfica de mulheres, adotando como ponto central as elaborações de Margareth Rago a partir do cuidado de si elaborado por Michel Foucault.

\section{As palavras, a coisa em si e os devires}

A instituição artística, assim como outras instituições sociais, apresenta um recorte onde dinâmicas de interação social se refletem e se constituem. Deste modo, observo como a arte contém e reproduz uma série de ações hierarquizadas e opressoras, como bem encontradas no sistema patriarcal e eurocêntrico em que o contexto da Arte se formou, e que reverbera em regiões outras a ele associadas. A costura dessa pesquisa parte de alguns pensamentos 
de autoras e autores apresentada/os acima, como Judith Butler, Michel Foucault, Donna Haraway, Margareth Rago, Guacira Lopes Louro, Danielle Kergoat e Linda Nochlin. A interação entre as formas de pensar dessa/es autora/es, junto a tanta/os outra/os, germinou na produção de conhecimento que busco apresentar nesse trabalho.

Inicialmente, para discutir uma problemática que envolva a sujeita mulher - bem como qualquer reconhecimento de identidade - é necessário adotar uma perspectiva que discuta essa identidade e em que plano ela se encontra. A perspectiva adotada nesse trabalho parte de uma compreensão de um feminismo pós-moderno que pensa o sexo/gênero como uma categoria socialmente construída e às quais uma miríade de expectativas e regras são associadas, o que pretende desfazer qualquer concepção naturalista de identidade (BITTENCOURT, 2015). Portanto, deslocar a identidade de uma inevitabilidade pré-discursiva atrelada à configuração biológica dos indivíduos permite trazer esse discurso ao campo político e social e discutir criticamente as redes de poder que se apoiam nessa lógica para sustentar sistemas de dominação.

Nesse sentido, Judith Butler (2003) pensa a própria ideia de gênero, e a forma como cada um portou-se historicamente, como advindas de regulações próprias da cultura, mutáveis em tempo e espaço, contestando a verdade permanente de uma natureza biológica. Dentro desse esquema patriarcal vigente, a distribuição dos papéis associados ao binarismo dividiu em dois polos opostos a figura feminina e masculina, instituindo à primeira a função do cuidado - seja do lar ou da família - e ao segundo a produtividade física e intelectual. Essa divisão das funções também se fez presente na divisão social dos espaços, bem como do trabalho, reforçando o 'pertencimento' das mulheres ao lar e dos homens à vida pública, aumentando o caráter silencioso dessa parti- cipação feminina na construção da história e da sociedade (KERGOAT, 2003).

Entendo, então, que essa divisão - e desigualdade - entre os gêneros associa-se a redes de poder bem estruturadas na sociedade e cuja sustentação necessita que esses papéis se mantenham estáveis e sob controle, confluindo com a ideia do exercício de poder como forma de disciplinar os sujeitos, segundo Michel Foucault (1999), e como esse poder atua sobretudo na regulamentação dos corpos e das identidades. A nomeação das categorias de sexo/gênero e a elaboração de regras de conduta - e possibilidade performativa - fazem parte de produções de saber e poder, pois nomear significa também delimitar, manter fixas as definições da identidade. Tanto Judith Butler (2003) e Susan Bordo (1997) como Michel Foucault (1979) compreendem o corpo como local onde essas regras foram amplamente instituídas, e que essa atuação do poder participou também da própria constituição de sujeito, elaborando que uma perspectiva identitária limitada fabricada pelos sistemas de dominação restringe o processo de subjetivação, e consequentemente de emancipação. A subjetivação é, tanto para Foucault (1979) como para Suely Rolnik (2016), uma das principais fontes de insurgência diante de uma estruturação que pretende minar o campo subjetivo e as identidades móveis ao taxar e categorizar os indivíduos de modo a facilitar o controle.

A escrita de si surge nesse cenário como uma prática de liberdade e subjetivação, e que numa narrativa de grupos não hegemônicos e identidades dominadas nessa configuração, adota um senso político ainda mais importante (RAGO, 2013). o próprio corpo como narrativa central surge no trabalho de Oriana a partir do encontro com a escrita de si, que provoca quebra de barreira e resistência no dizer-se:

O trabalho com a escrita de si me levou a perder o preconceito e, mais do que preconceito, 
eu era muito reativa com o dizer-se, o lançar-se à própria história e às próprias aflições e instigações. Mas, a gente está viva, tá entendendo? Então, vamos olhar um pouco para essa vida, e o que essa vida nos proporciona. Então, eu pedi a vergonha de assumir que a vida é a mola dessas proposições todas. (DUARTE, 2019) ${ }^{5}$

A narrativa autobiográfica propõe uma prática de extensiva reflexão sobre si e sobre os campos ao redor, ela promove uma postura ativa em que os processos de formação de sujeito perpassam ponderação e desligam do alienamento fabricado pelo sistema.

0 autorretrato assume nesse trabalho a função da escrita de si, pensando como narrar o próprio corpo permite desmanchar perspectivas tradicionais sobre o corpo de indivíduos, especialmente o feminino, e cortar as amarras da disciplina. Pondero sobre o corpo feminino, especificamente na arte, dada a dialética de um potencial criativo desencorajado e deslegitimado, em contraste à valorização e exaltação do corpo objeto de desejo. Nesse quesito, um corpo feminino emancipado, ativo e desejante contraria todas as expectativas que a instituição artística colocou em cima da passividade e borra os limites da disciplina do corpo. Assim, Oriana bem comenta: "o corpo é um lugar de complexidade, e trabalhar com ele é você realmente estar se lançando a um universo que não sabe qual é"6.

A partir dessa união de pensamentos, elaboro como o corpo de Oriana Duarte se torna híbrido por se modificar fisicamente e afetivamente de maneira constante, transformando-se em si mesmo e além de si mesmo numa mistura ciborgue e fronteiriça, e promove um discurso político diante dos dispositivos de poder. Penso o corpo híbrido como parte de uma identidade ciborgue, de misturas de corpo, máquina, objeto, em diluições pós-humanas. A existência ciborgue é, para Donna Hara-

5 Oriana Duarte em entrevista

6 Oriana Duarte em entrevista way (2009) “criaturas que são simultaneamente animal e máquina, que habitam mundos que são, de forma ambígua, tanto naturais como fabricados" (p. 36). A máquina pode ser entendida como qualquer ferramenta e dispositivo construído, qualquer tecnologia de extensão do próprio corpo - da carne, da pele, da mente.

Nesse sentido, o corpo híbrido está sempre se transmutando, de corpoambiente a corpoedifício, corpoanimal, corpoescuta em movimentos que extrapolam a limitação de mecanismos biológicos restritivos de possibilidades identitárias e corpóreas. Na verdade da artista não existem limites para a experiência no mundo, as identidades estão imersas em tantos campos quanto possivel numa existência ciborgue. Ser cirborgue não é ser desumana/o, mas sujeita/o além de si.

Nesse quesito, Donna Haraway (2009) coloca as identidades pós-modernas na superação das limitações da condição humana, cujas metamorfoses produzem uma identidade política não afiliada a categorias pré-definidas, sem territórios originários, sem um organismo determinante. Vejo aqui congruências com a perspectiva de Oriana Duarte pelas tecnologias de extensão da própria existência. Através das máquinas de musculação modifica a estrutura muscular pré-determinada, torna-se mais forte em ordem de conectar-se ao remo e tornar-se corpobarco: "alguém nota que sou um barco?" (DUARTE, 2013, p. 15) (Figura 1). 0 corpo torna-se para ela uma possibilidade de ultrapassar limites, como no trecho "meu corpo de superação, afora os elementos acoplados à sua forma, bem consegue ir mais além" (DUARTE, 2013, p.46). O corpo, para Oriana Duarte, não é um local de significados, mas um campo de possibilidade e experiência, constantemente disposto a promover transformações, 'uma aventura' (sic). ${ }^{7}$

7 Oriana Duarte em entrevista 
Figura 1 - corpobarco

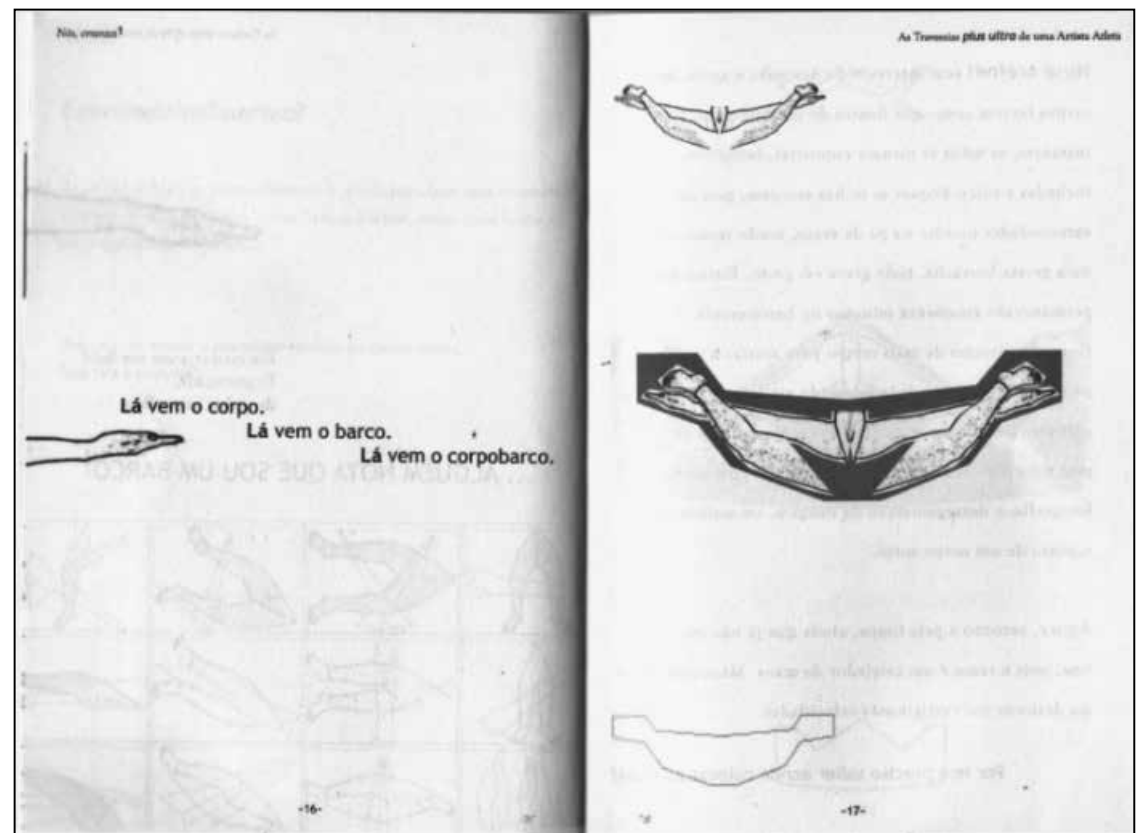

Fonte: As travessias de Plus Ultra livro 1, 2013

A exemplo, a performance-dissertação Dos Heteróclitos (2002) apresenta o período em que habitou o Edificio Copan na cidade de São Paulo, estabelecendo um contato entre corpo e espaço urbano, imersão de si num monumento, tornar-se parte deste. Observo nesse trabalho essa identidade pós-humana e pósmoderna, numa fuga da norma padrão sobre os corpos.

Em trabalhos tanto anteriores como posteriores, essa metamorfose costura constantemente seu fazer artístico, contestando as configurações predeterminadas do próprio corpo, como em A coisa em si (1997) em que coleta pedras de um local e ingere em forma de sopa em outro, digerindo e deslocando territórios, transmutando a rocha em fluido. Ou mesmo a transformação do corpo passivo em corpo ativo, como em Experimentos de Voos Artísticos (E.V.A) (2005) em que altera a estrutura muscular através dos aparelhos de musculação com a finalidade de realizar esportes radicais. A mutação desse corpo ainda corrompe a dualidade construída da figura feminina tanto da fragilidade e pureza como do pecado e desejo, ela não se apresenta como nem um nem outro, mas cria uma terceira, quarta e quantas possiveis representações. Não se trata de corresponder a uma identidade pré-programada, mas a se constituir na criação de outras formas identitárias, inclusive sem forma alguma (Figura 2).

Figura 2 - sem título

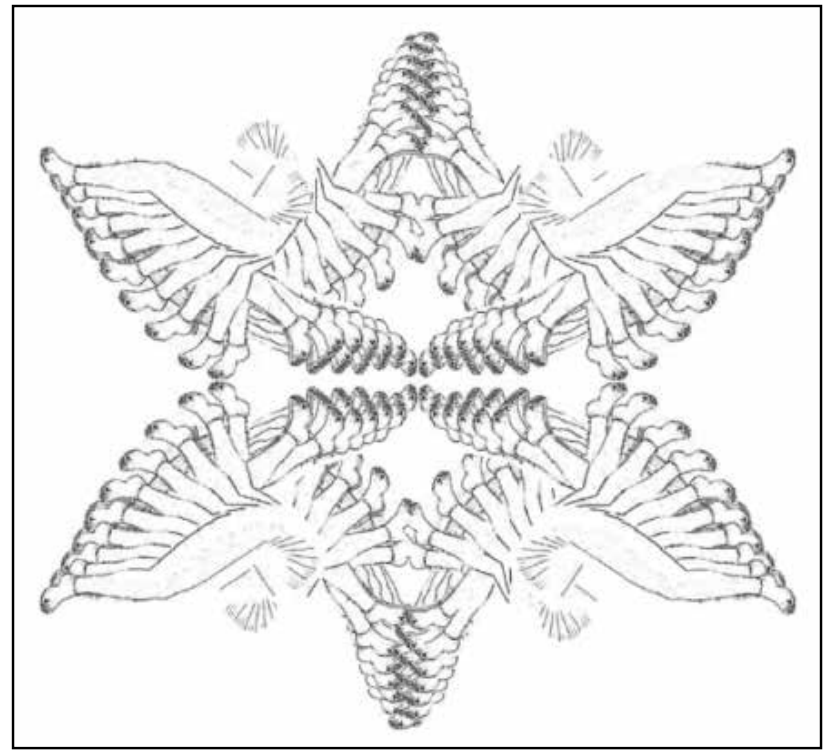

Fonte: Plus Ultra: o corpo no limite da comunicação, 2012

A ideia mesmo de heteróclito que Oriana Duarte apresenta em Dos Heteróclitos (2002) prevê uma existência instável e mutável, pois, o heteróclito, segundo Michel Foucault (1999), 
representa a impossibilidade de nomeação, promove a inquietação na linguagem ao desarrumar a estabilidade de definições.

o corpo entra nessa discussão como um lugar do discurso, onde as práticas de poder e obediência projetam paradigmas e atuam, e um dos principais mecanismos de controle do corpo surge na sociedade patriarcal mediante nomeação da sexualidade sob uma ótica heteronormativa e disciplinar, através de um discurso que delineia a prática sexual saudável como aquela restrita aos moldes conjugais heterossexuais e a prática dissidente como qualquer outra (FOUCAULT, 1999). Nesse jogo de poderes as regras de performatividade dos corpos recai de forma mais rígida e disciplinar sobre o corpo feminino - bem como corpos que se aproximem a esse contingente - configurando uma estratégia altamente durável de controle e subordinação (BORDO, 1997). Então, se em uma sociedade regida pelo sistema patriarcal, onde as possibilidades performativas e existenciais da/os sujeita/os são atreladas a concepções binárias de sexo/gênero que polarizam e hierarquizam a/os individua/os, categorias bem nomeadas e fixadas conferem segurança ao sistema (BUTLER, 2003).

Essa formulação pretende elaborar como um corpo feminino não assujeitado aos moldes normativos, que deseja para além da utilidade econômica e monitorada oferece uma possibilidade subversiva perante esse sistema de dominação. Esses moldes podem também ser entendidos como máscaras produzidas por uma realidade social e territórios fixos aos quais a/os sujeita/os de desejo podem grudar ou gorar, provocando atrito ou correspondência entre as expectativas do olho visivel - macropolítica - e a fluidez do desejo - micropolítica (ROLNIK, 2016). O que se entende por olho visivel e plano macropolítico, na perspectiva de Suely Rolnik (2016), são os territórios visíveis, as máscaras-molde associadas aos papeis sociais que indivíduos devem supostamente grudar - identificar-se. Em uma perspectiva estática não há deslocamento de desejo e consequentemente não há deslocamento de máscaras, uma vez grudada não mais poderia desgrudar. Em contrapartida, a subjetivação e os desdobramentos do processo de emancipar-se dos territórios engloba um outro plano, o da micropolítica, que penetra todas as camadas estruturais e leva em consideração os desejos e seus deslocamentos, as possibilidades múltiplas de transformação e instabilidade (ROLNIK, 2016).

A subjetivação como processo de devires flexíveis e desterritorializados soma nesse trabalho à noção da escrita de si e cuidado de si como uma forma de subjetivação, como bem defendido por Margareth Rago em consonância com Michel Foucault, entendendo que a/o sujeita/o se constitui ao passo que rememora e une peças de vivência na construção de novas formas de ser, que a/o indivíduo cria e denuncia sua verdade, negando a narrativa vertical e distanciada de outrem e construindo uma própria (RAGO, 2013).

Diante desse cenário, o autorretrato e escrita de si se fazem como discurso político por figurar uma prática de liberdade, por atuar na criação da subjetividade, promoção de autonomia e fazer crítico que promove ruptura nos territórios e na estrutura patriarcal. Essa escrita de si permite a criação de sujeitas autônomas e autogovernadas, distantes dos olhares e expectativas alheias, ela abre espaço para a dissolução de mundos e formação de novas identidades e novos significados "capazes de escapar às tecnologias do dispositivo biopolítico de controle individual e coletivo" (ROLNIK, 2016, p. 43). Se, segundo Emma Goldman “a melhor muralha da autoridade é a homogeneidade" (2007:1940, p.36), subjetividades múltiplas e fluidas tornam-se um perigo necessário para desarrumar estruturas de poder. Nesse sen- 
tido, a escrita de si, bem como o cuidado de si promovem a construção de uma ética própria, ética esta que desemboca em caminhos de liberdade, visto que desloca a sujeição da confissão de si a um Outro - como nas práticas cristãs - e a direciona inteiramente para si (FOUCAULT apud DUARTE, 2012).

$\mathrm{O}$ autorretrato em questão, Selvagem Sabedoria (2004) (Figura 3), inaugura a série de pesquisas com próprio corpo, via investigações de seus limites e como extrapolá-los. A obra surge pelo retorno a si, mergulho nas angústias, sofrimentos e no desejo de inflamar de vida o corpo diante da morte, animalizar-se no enfrentamento de medos da condição mortal. Oriana comenta:

\begin{abstract}
Nesses anos que antecedem minha tensão com o corpo, vivi um luto muito dramático, que foi a perda da minha mãe, muito jovem, vivi o acompanhar do corpo que vai perdendo a vida, numa situação realmente limite, e é algo que é muito chocante. De fato, eu precisava ativar o corpo para poder viver a morte. Por exemplo, a Selvagem Sabedoria mesmo, a experiência de você estar lidando com uma cobra, viver trancada uma semana com a cobra só sentindo medo, sem conseguir fazer nada com essa cobra a não ser sentir medo. E tem uma imagem o tempo inteiro na sua cabeça, que é uma imagem que suscitava uma imagem da arte, um palimpsesto da arte. [...]. Como se só a arte pudesse estar ali convivendo com o medo (DUARTE, 2019) 8 .
\end{abstract}

A cobra representa a sabedoria e a primeira pecadora do mundo - Lilith. Nesse processo a artista apresenta-se nua de costas com uma cobra-cipó enrolada no pescoço, promovendo uma crítica à História da Arte tradicional que tanto erotizou o corpo feminino ao reescrever a obra Le Violon d'Ingres (1924) de Man Ray. Oriana realiza um palimpsesto que reescreve as significações anteriores do corpo feminino passivo transformando-o em corpo ativo, pulsante de desejo e emancipado. Ela levanta

8 Oriana Duarte em entrevista símbolos e contextos de uma outra época para criticar um fazer opressor e regulador sobre corpos, constrói novos significados apresentando-se de forma crítica e deserotizada.

Figura 3 - A Selvagem Sabedoria

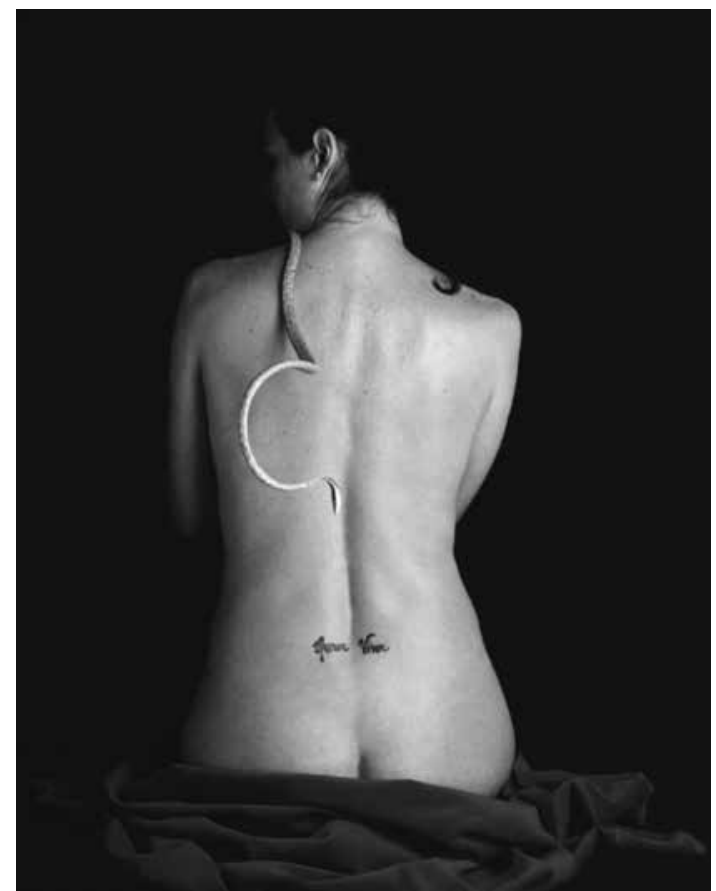

Fonte: Coleção particular

Esse palimpsesto atua como uma análise crítica de uma obra-texto anterior, como a exercer o papel de 'imagem crítica' tida por Didi-Huberman como:

Uma imagem que critica a imagem - capaz portanto de um efeito, de uma eficácia teóricos -, e por isso uma imagem que critica nossas maneiras de vê-la, na medida em que ao nos olhar, ela nos obriga a olhá-la verdadeiramente. E nos obriga a escrever esse olhar, não para 'transcrevê-lo' mas para constituí-lo" (DIDI-HUBERMAN, 2018, p. 172).

O jogo de olhares sobre as obras não atende à simples transcrição do que contém a imagem, mas constrói significados sobre elas, pretende traçar contextos e discursos histórico -político-sociais sobre categorias e indivíduos, dialogando constantemente com também um fazer possivelmente transformador, no intuito de conceber caminhos outros às formas de olhar no campo da arte. Assim como Didi-Hu- 
berman (2018) entende a imagem dialética em ambiguidade e deformações de sentidos, entendo tanto o conjunto do trabalho de Oriana Duarte como A Selvagem Sabedoria nessa deformação instável e metamórfica da identidade e em constante desconstrução de significações anteriores sobre corpo de artista, corpo feminino, sobre domínio e escrita de si. Para Oriana Duarte, essa obra representa um fazer político por tratar-se de um escape à ordem, enquanto provoca incômodo, como é possivel observar na passagem:

Uma fala que se posiciona no sistema, seja contra, seja a favor, seja escapando completamente... eu estou no escape, estou cortando, eu estou transversalizando esse sistema. Que é o que mais incomoda, que é o que eu mais gosto também, que é de incomodar, que é uma atitude política. (DUARTE, 2019)9.

O que propõe essa pesquisa é a apresentação de uma nova forma de entender o autorretrato, somando a ele a uma possibilidade de discurso político quando associado à prática de artistas mulheres por configurar uma forma de escrita de si constitutiva, que não se restringe à denuncia a verdade de sujeita/o mas também a constrói. Ser mulher e criar é por si só um ato político, e incorporar esse discurso produzindo nova visualidade sobre o corpo abre portas para novas construções de subjetividade, e, consequentemente, atuações micropolíticas insurgentes às instituições dominantes.

\section{Considerações finais}

Propus ao iniciar essa pesquisa investigar de que forma o autorretrato, quando associado à pratica de artistas mulheres, poderia portar um discurso político. Tomando como objeto o autorretrato Selvagem Sabedoria de Oriana Duarte, me permiti mergulhar na poética

9 Oriana Duarte em entrevista da artista, abrindo as portas para o encontro entre meu corpo vibrátil e o dela de modo a corroborar ou contrariar as hipóteses previamente elaboradas. Após o encontro, pude perceber que as implicações políticas da obra em questão iam muito além daquilo que havia suposto, o discurso político não surge apenas numa narrativa própria sobre o corpo, ele surge principalmente no desmanchar desse corpo e nas ondulações que grudam-e-desgrudam em outros campos para fora de si. A poética da artista se faz no deslocamento, no ir e vir de vivências temporárias e transformadoras. A arte emerge como um campo de possibilidades, um lugar em que tudo pode ser ou não e esse é o discurso político, é poder criticar sistemas, criar novas significações e promover realidades possíveis. Não há uma verdade estática a ser produzida, mas aqui elaboro a verdade de uma artista que faz arte de sua vida, que pensa sobre o corpo enquanto extrapola ele, se acopla a maquinários ou animais, ou mesmo a nada, cria alternativas para exploração do corpo de maneira horizontal, diagonal, interna ou externa, mas jamais vertical e hierárquica.

Diante de sistemas de dominação, tornar-se massa homogênea e reprodutora de discursos é uma forma de sustentá-lo, então, dedicar-se a subjetivação e desafixar territórios é um ato político de insubordinação. Oriana Duarte encontrou na arte um terreno fértil para ação e transformação, a prática artística se constrói enquanto prática de liberdade e produção de subjetividade mediante a elaboração de uma verdade própria..

A discussão apresentada pode se fazer em qualquer sujeita/o fluida/o, desterritorializada/o e, portanto, subversiva/o. Aqui, penso como a pós-modernidade desfaz um pensamento racional e categórico, obsoleto e opressor, que mediante longa tradição silenciou sujeita/os não hegemônica/os e marginalizou as identidades plurais como forma de perpetuar 
sua dominação. Esse mundo de possibilidades que a pós-modernidade busca incorporar é o que permite que trabalhos como este sejam pensados e executados, criticados ou tomados como relevante. Por se tratar de uma pesquisa cujo ponto central é o deslocamento de significações e transgressão de limites, delimitar uma conclusão torna-se quase incongruente, porém, o que colho desse trabalho é mais uma forma de produzir subversões aos paradigmas, pensar em identidades políticas e como os desejos e subjetivações, as microatuações, podem somar em atitudes políticas de desconstrução.

0 que foi possivel aprender com essa pesquisa foi a potência que carregam corpos instáveis e híbridos, que se desfazem das máscaras obsoletas de um formato de identidade, e que por sua instabilidade desestruturam as regras anteriores de controle dos corpos baseada na normatividade sexual binária. Também resultou da análise a importância que um fazer artístico autobiográfico pode ter nesse contexto, e que é possível com uma imagem raspar significações anteriores também anacrônicas e emancipar-se nesse processo autonarrativo, em produção de verdade própria. A conclusão última que apresento aqui é: sejamos toda/os ciborgues, sejamos toda/os instáveis e esquiva/os ante estratégias de dominação e disciplina.

\section{Referências}

ABRAHÃO, Maria Helena. Memórias, narrativas e pesquisa autobiográfica. In: História da educação (ASPHE). Pelotas: Editora da UFPel.v.14, n1, p. 79-95, 2003. Disponivel em: https://www.seer.ufrgs.br/ asphe/article/viewFile/30223/pdf . Acessado em: 30/03/2020.

ARCHER, Michael. Arte Contemporânea: uma história concisa. São Paulo: Martins Fontes, 2008.

BARROS, Regina Benevides; PASSOS, Eduardo. A cartografia como método de pesquisa-intervenção.
In: PASSOS, Eduardo. KASTRUP, Virgínia. ESCÓSSIA, Liliana da. (Org). Pistas do método da cartografia: pesquisa-intervenção e produção de subjetividade. Porto Alegre: Sulina, 2015. p. 17-32.

BOTTI, Mariana Meloni. Espelho, Espelho meu?: auto-retratos fotográficos de artistas brasileiras na contemporaneidade. 2005. 153 p. Dissertação. (Mestrado em) Multimeios, UNICAMP, Campinas, 2005.

BORDO, Susan. O corpo e a reprodução da feminidade: uma apropriação feminista de Foucault. In: JAGGAR, Alison M.; BORDO, Susan R (orgs.). Gênero, corpo, conhecimento. Rio de Janeiro: Rosa dos Tempos, 1997. p. 19-42.

BUTLER, Judith. Corpos que pesam: sobre os limites discursivos do 'sexo'. In: LOURO, G. L. (Org.). 0 corpo educado: pedagogias da sexualidade. 2 a ed. Belo Horizonte: Autêntica Editora, 2000. p. 110-127.

Problemas de gênero. Rio de Janeiro: Civilização Brasileira, 2003.

DIDI-HUBERMAN, Georges. 0 que vemos, o que nos olha. 2a ed., 3a reimpressão. São Paulo: Editora 34, 2018.

DUARTE, Oriana. Dos heteróclitos como categoria de ação. São Paulo: Bienal, 2002.

Usei meu corpo: das vísceras fiz sopa, dos membros fiz pontes. In: Associação Brasileira De Pesquisa E Pós-Graduação Em Artes Cênicas (Congresso), 5a ed., 2008. Belo Horizonte. Anais... Belo Horizonte, ABRACE, 2008. p. 1-4

Oriana Duarte. In: Cristiana Tejo (Org.). Salto no Escuro: curadoria de arte como experimento. Recife: Funcultura, 2011. p.66-81.

Plus Ultra: o corpo no limite da comunicação. 2012. 317p. Tese (Doutorado) Programa de Pósgraduação em Comunicação e Semiótica, Pontificia Universidade Cat́locia de São Paulo, São Paulo, 2012.

Nós, errantes: as travessias plus ultra de uma Artista Atleta. Parte I. Recife: Editora Universitária UFPE, 2013.

O entre arte e filosofia: um pensar sobre es- 
tilo de existência e vida de artista. In: Associação Nacional De Pesquisadores Em Artes Plasticas - Ecossistemas Artisticos (Simpósio), 23a ed, 2014, Belo Horizonte, Anais... Belo Horizonte, ANPAP, 2014. p. 3409-3417.

FOUCAULT, Michel. Microfísica do poder. Organização e tradução de Roberto Machado. Rio de Janeiro: Edições Graal, 1979.

. A escrita de si. In: FAUCAUL, Michel. $\mathbf{0}$ que é um autor? Lisboa: Passagens. 1992. p. 129-160

. História da sexualidade. 13 ed. Rio de Janeiro: Graal, 1999a.

As palavras e as coisas. 8 ed. São Paulo: Martins Fontes, 1999b.

GARCIA, Carolina; SCHUCK, Elena. O feminismo de Ana Mendieta no campo das artes visuaus. In: Seminário Internacional Fazendo Gênero \& Mundos De Mulheres. (Seminário), $11 \& 13$, 2017. Florianópolis. Anais eletrônicos... Florianópolis, UFSC, 2017. p. 1-11.

GATTI, Fábio Luiz. Auto-retrato: A expressão fotográfica e o desenho simbólico. In: Associação Nacional De Pesquisadores Em Artes Plásticas, Transversalidades Nas Artes Visuais (Simpósio), 18aed, 2009, Salvador. Anais... Salvador, EDUFBA,2009. p. 411-425

GOLDMAN, Emma. 0 indivíduo, a sociedade e o estado. São Paulo: Hedra, 2007.

HARAWAY, Donna. Saberes localizados: a questão da ciência para o feminismo e o privilégio da perspectiva patriarcal. Cadernos Pagu. Campinas, v. 5, p. 0741, 1995. Disponivel em: https://periodicos.sbu.unicamp.br/ojs/index.php/cadpagu/article/view/1773 Acessado em: 20 agost. 2018.
HARAWAY, Donna; TADEU, Tomaz; KUNZRU, Hari. Antropologia Ciborgue: As Vertigens do Pós-Humano. Belo Horizonte: Autêntica Editora, 2009

KERGOAT, Danielle. Divisão sexual do trabalho e relações sociais de sexo. In: TEIXEIRA, M. (org.). TrabaIho e Cidadania Ativa para Mulheres: desafios para as políticas públicas. São Paulo: Coordenadoria Especial da Mulher, 2003. p. 55-65.

LOURO, Guacira Lopes. 0 corpo educado: pedagogias da sexualidade. Belo Horizonte: Autêntica, 2015.

NOCHLIN, Linda. Why Have There Been No Great Women Artists? In. NICHOLIN, Linda. (Ed.). Women, Art and Power and Other Essays. New York: Westview Press, 1988. P. 25-40.

PERROT, Michelle. Minha história das mulheres. São Paulo: Contexto, 2007.

POLLOCK, Griselda. Vision y diferencia: feminismo, feminilidad y historias del arte. Buenos Aires: Fiordo, 2013.

RAGO, Margareth. A aventura de contar-se: feminismos, escrita de si e invenções da subjetividade. Campinas: Editora da Unicamp, 2013.

ROLNIK, Suely. Cartografia sentimental: transformações contemporâneas do desejo. 2a ed. Porto Alegre: Sulina; Editora da UFRGS, 2016.

ZACCARA, Madalena. De sinhá prendada a artista visual: os caminhos da mulher artista em Pernambuco. Recife: Ed. do organizador. 2017

Recebido em: 15.10 .2019

Revisado em: 26.03.2020

Aprovado em: 30.03 .2020

Ana Carolina Magalhães Salvi é mestre pelo Programa de Pós-Graduação em Artes Visuais da Universidade Federal de Pernambuco (UFPE). E-mail: anacsalvii@gmail.com 